\title{
The Ethics of Storytelling: Narrative Hermeneutics, History and the Possible
}

Hanna Meretoja (2018) New York: Oxford University Press. 368pp. $£ 69$ (hardback)

ISBN: 9780190649364

Reading Hanna Meretoja's The Ethico of Storytelling has been a pure pleasure. It is a book carefully researched, rigorously theorised, well designed and beautifully written. It is a philosophical contribution to narrative theory, which nevertheless captures you like a novel and from its very first pages achieves what its subtitle promises: to open up possibilities of understanding, rethinking and re-imagining the force of storytelling through the lens of narrative bermeneutics. Although Meretoja is a literary scholar her take on the concept of narrative bermeneutics, as well as her philosophical exploration of the ethics of storytelling apply to both fictional and non-fictional narratives, following a line of thinkers who explore multifarious connections between literature, auto/biographies and history/ies.

The book is organized in two main parts: a thorough theoretical exposition of narrative hermeneutics and the ethics of storytelling in Chapters 1, 2 and 3, followed by 4 exemplars of applied narrative hermeneutics, particularly exploring: a) moral agency in Julia Frank's novel, The Blind Side of the Heart (Chapter 4), connections between history and fiction in Günter Grass' novels and autobiography (Chapter 5), interfaces of content and form in Jonathan Little's perpetrator novel, The Kindly Ones (Chapter 6) and the ethical potential of the dialogic in David Grossman's storytelling (Chapter 7). This organization gives readers the option either to engage with the whole book or simply to delve into the first part, if they are less interested in literary theory and criticism. Although my interest in narrative theory and philosophy comes from my readings of auto/biographical narratives, I recommend an engagement with the entire book, because it is through the details and specificities of the four exemplars that the power of the author's theoretical contribution is most clearly displayed.

As a Foucauldian scholar, I admit I was initially apprehensive of the much discussed, criticized and deconstructed notion of hermeneutics, but was eventually persuaded by the author's reconfiguration 'as an endless activity of (re)orientation, engagement and sensemaking, which is thoroughly worldly, both in the sense of being embedded in a social and historical world and in the sense of participating in performatively constituting that world' (p.10). I also agree that the author's four dimensions of the ethics of story-telling as a) reflective-analytic; b) transcendental, c) evaluative and d) explorative open up new vistas in conceptualizing and engaging with the complex field of ethics in narrative inquiries and beyond.

I cannot deny I was often ambivalent while reading this book and I will offer my doubts below as a way of opening up more dialogic spaces between me, the author and the wider audience of those who consider narrative theory and research.

a. While fully agreeing with Meretoja's take on narrative imagination, I am uncertain as to its connection with the idea of a narrative unconscious, despite the author's reassurance that her take on the unconscious is not psychoanalytically limited and thereby constrained. Meretoja explicates the notion with reference to the ways that 'the cultural mechanisms that regulate how we narrate our experiences and share them with others affect us largely unconsciously' (p.19). My own critique here derives from my engagement with process philosophy and narrative understanding. 
As I have argued elsewhere (Tamboukou 2016), we should not downplay 'how matter matters' not just as material conditions of possibility for 'cultural mechanisms' to emerge and unfold, but as dynamically intervening not only in how we 'feel' narratives, but also and, perhaps more importantly, in how we fail to see or recognise them. My perception of this dim area of latent narratives is very close to the field of unrealized possibilities which Meretoja elaborates in her take on narrative hermeneutics; however, I would not describe it as 'unconscious', rather as precognitive narrative entanglements of matter and meaning.

b. While I agree that experience is not determined, but only conditioned, I would also add that 'the new' that we are always 'capable of experiencing' (p.46) is always, already there, part of the ontological make-up of the world we experience. So, from the lens of process philosophy again, 'the cognitive and the affective are not [just] irreducibly intertwined' (p.46). The affective actually precedes the cognitive: we feel the world (and its narratives among other ontical characters or events) and then we recognize it and understand it - 'the basis of experience is emotional' for Whitehead $(1967,176)$.

c. In laying out the circle of interpretation, Meretoja highlights the importance of considering various perspectives. Perspectivism is indeed important, but what I think can be developed more in a narrative hermeneutics plane of analysis is the entanglement of the listener in the process of understanding. Meretoja's perspective is mostly situated in literary theory, so it is understandable that the listening situation has taken a back seat, but I think that some of her insights can open up interesting areas in the ethics of oral history and narrative interviews.

d. I recognise that Meretoja's careful examination of the 'anti-narrativist' camp and particularly Strawson's thesis is careful, nuanced and to the point. However, it comes from a non-materialist's perspective. A Whiteheadian approach to narratives would find Strawson's thesis more persuasive, but would also fill in the gaps of his 'pearl view' theorization of the self (see p. 56) through the permanence/flux continuum. Namely, the idea that while the world, as well as human subjects as part of it, keep changing, there is always 'the stubborn fact' of the past that stays behind, forming what we recognise as the historic world and therefore the historic part of the self and its traces in narratives.

e. Materiality could also have been discussed more within the dialogics of narrative hermeneutics as it would have opened up more space for objects and artefacts of the material culture to enter the cycle of interpretation.

The ambivalences I highlight above are offered as entry points for more discussions between narrative hermeneutics and new materialism philosophies, an area that is at the heart of my interest and scholarship while reading the book and writing this review. They definitely reflect the reviewer's perspective on the rich insights that Meretoja's analysis and scholarship offer. The Etbics of Storytelling is an excellent book and has already made a significant contribution to the theories and philosophies of narrative research.

\section{References}

Tamboukou, Maria. 2016. Gendering the Memory of Work: women Workers' Narratives. London: Routledge.

Whitehead, North, Alfred. (1967[1933]) Adventures of Ideas. New York: Free Press. 
Dr Maria Tamboukou, Leverhulme Research Fellow University of East London, UK

m.tamboukou@uel.ac.uk 